\title{
Design of Novel Hexagonal Shape Microstrip Patch Array for Bluetooth, WLAN and WiMAX Applications
}

\author{
Chaw Myat Nwe \\ Department of Electronic Engineering \\ Mandalay Technological University \\ Mandalay, Myanmar
}

\author{
Khaing Wai Pyone \\ Department of Electronic Engineering \\ Technological University (Loikaw) \\ Loikaw, Myanmar
}

\begin{abstract}
Today dual or multiband antenna has been playing a vital role for wireless service requirements. This paper presents a $1 \times 2$ hexagonal shaped patch array for Bluetooth, WLAN and WiMAX applications. Array antennas are used to enhance performance especially in gain of the antenna. The presented antenna is designed a size of $50 \times 50 \times 1.6 \mathrm{~mm}^{3}$ on a FR4 substrate and covers the frequency range from 2.4 to $5 \mathrm{GHz}$, with bandwidth $2.6 \mathrm{GHz}$ and 5.5 to $6.36 \mathrm{GHz}$, with bandwidth $860 \mathrm{MHz}$. The maximum directivity gain achieved here is $4 \mathrm{dBi}$. The micro strip feed line is defected in order to enhance the return loss and cover the desired frequency range of antennas. The antenna has input impedance of $50 \mathrm{ohms}$ to achieve the maximum power transfer and ensuring minimum reflection losses.
\end{abstract}

Keywords- Microstrip Patch Array Antenna; Gain; Bandwidth; Feed Techniques; Dielectric.

\section{INTRODUCTION}

As current and future technology trends in wireless communication have increased, the demand for patch antennas that can work at various bands with sufficient bandwidth will more needed. Design requirements have encouraged that antenna researchers need to design a multiband antenna with the purpose to improve the wireless quality and increase the application areas. Besides these, multiband antennas also fulfill their success in the field of cost, size and high data rate features. In this research work, a $1 \times 2$ hexagonal shape patch array antenna with micro strip line feed is designed for applications such as Bluetooth operating at $2.4 \mathrm{GHz}$ and WLAN frequency bands at $3.3 \mathrm{GHz}, 3.5 \mathrm{GHz}$ and WiMAX .

Microstrip antenna suffers from bandwidth limitations. The bandwidth can be increased by adding loss elements but it affects efficiency of the antenna. So the better method is to use array antenna. Micro strip antennas are used in arrays as well as single elements [2].

By using array in communication systems we enhance the performance of the antenna like increasing gain, directivity scanning the beam of an antenna system, and other functions which are difficult to do with the single element. This antenna is simulated using FEKO software. The simulated performances of the antenna such as gain, S-parameter and radiation pattern are measured.

\section{ANTENNA DESIGN}

\section{A. Substrate consideration}

Micro strip patch antennas consist of very thin metallic strip placed on ground plane where the thickness of the metallic strip is restricted by $\mathrm{t}<<\lambda_{0}$ and the height is restricted by $0.0003 \lambda_{0} \leq \mathrm{h} \leq 0.05 \lambda_{0}$. There are numerous substrates that can be used for the design of micro strip antennas and their dielectric constants are usually in the range of $2.2 \leq \varepsilon_{\mathrm{r}} \leq 12$ [1] [2]. According to the restricted and easily find in Myanmar market, $1.6 \mathrm{~mm}$ thick FR4-epoxy substrate, with a permittivity of 4.4 and loss tangent 0.018 are chosen to obtain optimal design.

\section{B. Patch Width}

The patch width depends on the two parameters like center frequency and dielectric constant of materials.

$$
W=\frac{c}{2 f_{o} \sqrt{\frac{\varepsilon_{r}+1}{2}}}
$$

Where, $\mathrm{W}=$ Width of Substrate Material

$$
\begin{aligned}
& \mathrm{f}_{0}=\text { Centre Frequency } \\
& \varepsilon_{\mathrm{r}}=\text { Relative Permittivity or Dielectric Constant. }
\end{aligned}
$$

\section{Effective Dielectric Constant}

Effective dielectric constant $\varepsilon_{\text {eff }}$ is introduced to account for fringing and the wave propagation in the line. $\varepsilon_{\text {eff }}$ can be found by the following mathematical relationship.

$$
\varepsilon_{e f f}=\frac{\varepsilon_{r}+1}{2}+\frac{\varepsilon_{r}-1}{2}\left[1+\frac{12 h}{w}\right]^{-0.5}
$$

Where, $\varepsilon_{\mathrm{eff}}=$ Effective Dielectric Constant

$$
\mathrm{h}=\text { Height of Substrate Materials. }
$$

\section{Effective length}

After the value of $\varepsilon_{\text {eff }}$ is calculated, the effective length of the patch $\mathrm{L}_{\mathrm{eff}}$ now becomes:

$$
L_{\text {eff }}=0.5 \frac{\lambda}{\sqrt{\varepsilon_{r}}}
$$




\section{E. Length Extension}

To calculate effective length extension at each side along the patch, $\Delta \mathrm{L}$ by the equation:

$$
\Delta L=0.412\left(\frac{\varepsilon_{r e}+0.3}{\varepsilon_{r e}-0.3}\right) \frac{\left[\frac{w}{t}+0.264\right] h}{\left[\frac{w}{t}+0.8\right]}
$$

\section{F. Patch Length}

The dimensions the patch along its length have now been extended on each end by a distance $\Delta \mathrm{L}$, the patch length (L) equation now becomes

$$
L=L_{\text {eff }}-2 \Delta L
$$

\section{G. Other parameters for circular patch}

Other parameters for designing the hexagonal shape are reactance of circular patch and resonance frequency. Primarily, circular patch is designed to be resonated at the fundamental resonance frequency which is approximately given by: $\mathrm{X}_{\mathrm{mn}}=1.8411, \mathrm{f}_{\mathrm{r}}=3.3 \mathrm{GHz}$. The effective radius of the circular could be calculated based on the height, dielectric constant.

$$
f_{r}=\frac{X}{2 \pi a_{e} \sqrt{\varepsilon_{r}}} c
$$

Where, $\mathrm{X}_{\mathrm{mn}}=$ Reactance of Circular Monopole Antenna

$$
\begin{aligned}
\mathrm{a}_{\mathrm{e}} & =\text { Effective radius of the circular patch } \\
\mathrm{c} & =\text { Velocity of light in free space. }
\end{aligned}
$$

The effective radius of the circular could be calculated based on the height, dielectric constant.

$$
a_{e}=a\left[1-\frac{2 h}{\pi a \varepsilon_{r}}\left(\ln \frac{\pi}{2 h}+1.7726\right)\right]^{\frac{1}{2}}
$$

In the above expression, ' $a$ ' is the actual radius of the circular patch antenna.

The side length of hexagonal patch antenna is

$$
\pi a_{e}^{2}=\frac{3 \sqrt{3}}{2} s^{2}
$$

Ground plane of substrate can be calculated the following.

$$
\begin{aligned}
& L_{g}=L+6 h \\
& w g=w+6 h
\end{aligned}
$$

Micro strip feed line of array is

$$
L=\frac{\lambda}{4}=\frac{\lambda_{0}}{4 \sqrt{\varepsilon_{\text {reff }}}} .
$$

and feed line width $\mathrm{W}_{\mathrm{o}}$

$$
z=\frac{120 \pi}{\left.\sqrt{\varepsilon_{r}\left[\frac{h}{w}\right.}+1.393+0.667 \ln \left(\frac{h}{w}+1.444\right)\right]}
$$

By using above equations, hexagonal shape micro strip patch array dimensions are shown in Table 1 . All of these parameters were selected to achieve compact $1 \times 2$ hexagonal shape antenna design .Here two patch elements are used and each element has same dimensions as mentioned above in order to increase antenna performance.

TABLE I. THE DIMENSIONS OF THE DESIGNED ANTENNA
\begin{tabular}{|c|c|c|c|}
\hline $\begin{array}{c}\text { Design } \\
\text { Parameters }\end{array}$ & $\begin{array}{c}\text { Length in } \\
(\mathbf{m m})\end{array}$ & $\begin{array}{c}\text { Design } \\
\text { Parameters }\end{array}$ & $\begin{array}{c}\text { Length in } \\
(\mathbf{m m})\end{array}$ \\
\hline $\mathrm{W}_{\mathrm{g}, \mathrm{L}_{\mathrm{g}}}$ & 50,24 & $\mathrm{a}$ & 7.5 \\
\hline $\mathrm{W}, \mathrm{L}$ & 50,50 & $\mathrm{~s}$ & 10 \\
\hline $\mathrm{W}_{\mathrm{f}}$ & 3 & $\mathrm{~h}$ & 1.6 \\
\hline $\mathrm{W}_{1}, \mathrm{~W}_{2}$ & $8.2,10$ & $\mathrm{E}_{\mathrm{r}}$ & 4.4 \\
\hline $\mathrm{L}_{1}, \mathrm{~L}_{2}, \mathrm{~L}_{3}$ & $3,1.4,5$ & Feed point & 0.35 \\
\hline
\end{tabular}

Fig.1 shows the general configuration of proposed hexagonal shaped patch array. Where $1 \times 2$ diamond shaped patch array is placed over the substrate having dielectric constant of 4.4 and the thickness of substrate is $1.6 \mathrm{~mm}$ and ground plane is printed on other side of the patch.

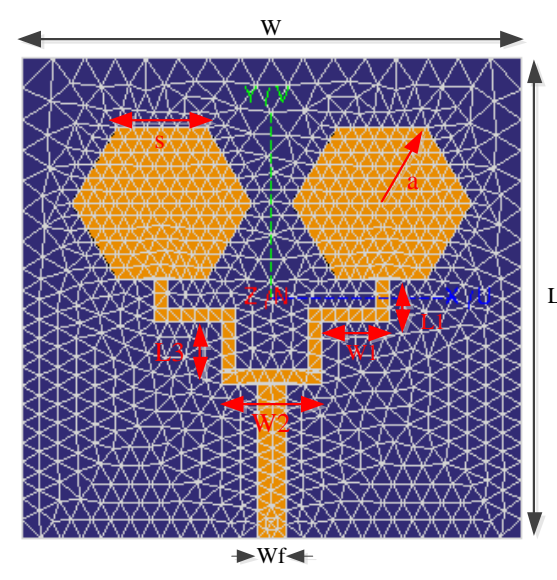

(a) 


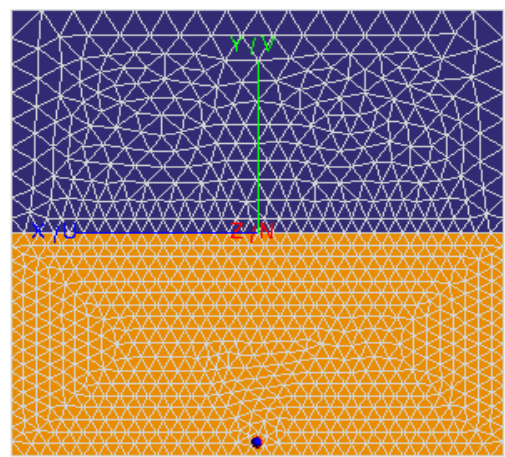

(b)

Fig.1 Design of 1x2 Hexagonal Patch Array Antennas

(a) Front view (b) Bottom view

\section{RESULT}

\section{A. S-parameter plot for return loss versus frequency}

Return loss is an important parameter when testing an antenna. It is related to impedance matching and the maximum transfer of power theory. It is also a measure of the effectiveness of an antenna to deliver of power from source to antenna. S-calculation has been performed for hexagonal micro strip $1 \times 2$ array antennas. Fig. 2 shows the antenna operates at a dual frequency band of 2.4 to $5 \mathrm{GHz}$, with bandwidth $2.6 \mathrm{GHz}$ and 5.5 to $6.36 \mathrm{GHz}$, with bandwidth $860 \mathrm{MHz}$. The simulated results shows the maximum return loss at $-32 \mathrm{~dB}$ and $-50 \mathrm{~dB}$ which can cover Bluetooth, WiMax and WLAN application.

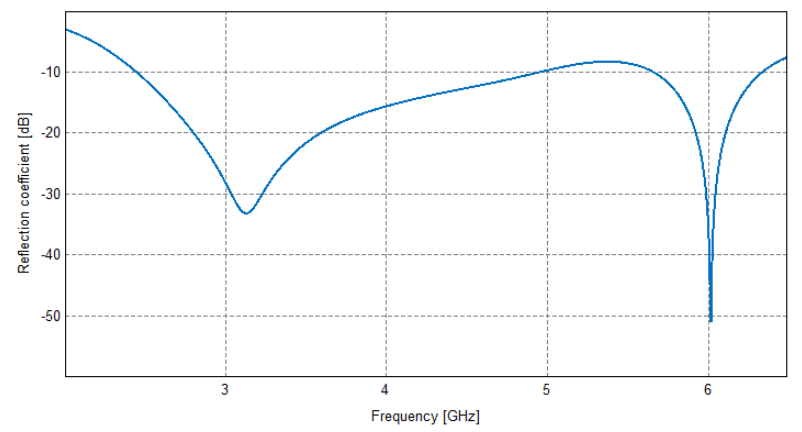

Fig. 2 Return Loss of 1x2 Array Patched Antenna

\section{B. Radiation Pattern}

The simulated radiation patterns of the designed antenna are plotted using CADFEKO EM-simulation software and validated results are given in Fig. 3 through 5 at three different resonating frequencies of $(2.4 \mathrm{GHz}, 3.35 \mathrm{GHz}$ and $5.54 \mathrm{GHz}$ ). The designed antenna shows radiation pattern nearly omnidirectional in $\mathrm{H}$-plane and bi-directional in Eplane, provided that antenna has good radiating properties at their operating bands.
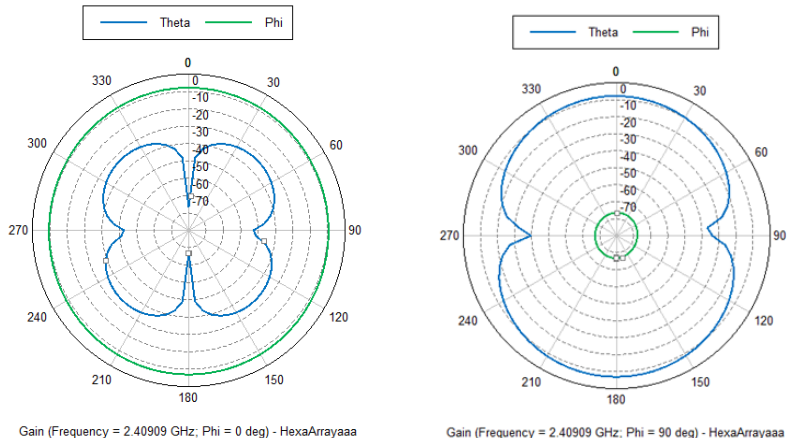

Gain (Frequency $=2.40909 \mathrm{GHz} ;$ Phi = 90 deg) - HexaArrayaaa

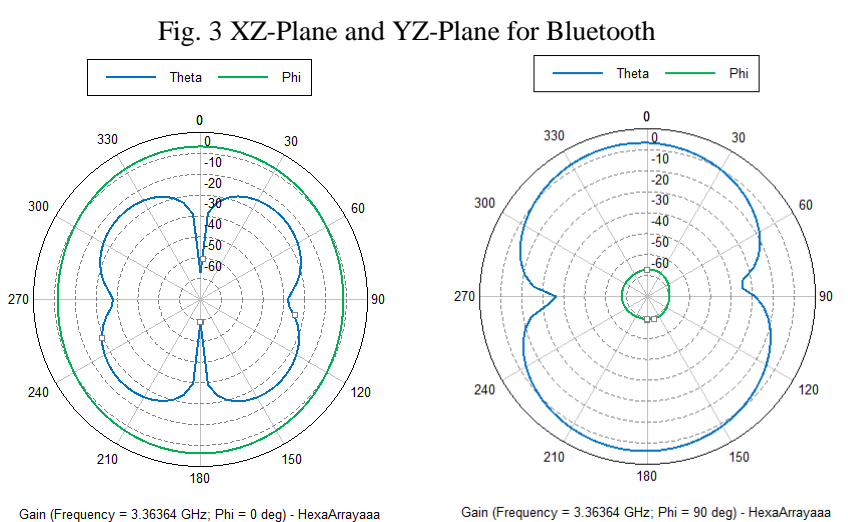

Fig. 4 XZ-Plane and YZ-Plane for WiMAX
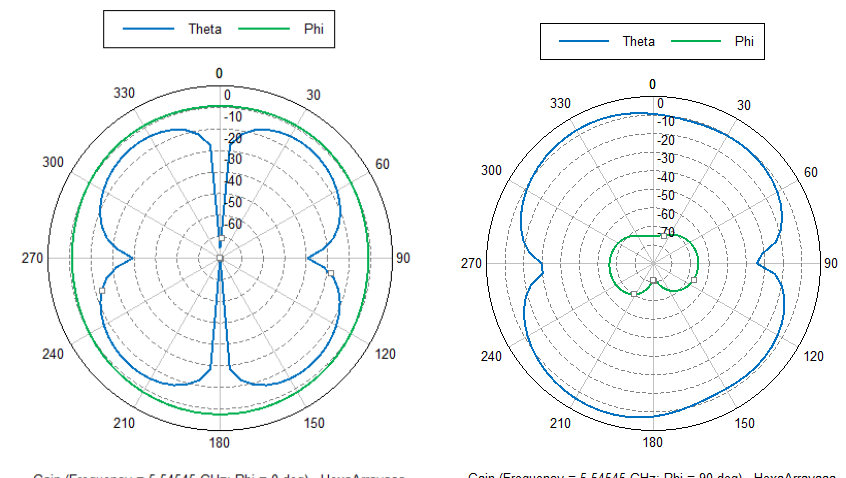

Fig. 5 XZ-Plane and YZ-Plane for WLAN

\section{3D Directivity Gain}

3D radiation of the antenna can be found from the Fig.6. According to the radiation pattern, the type of the antennas can be said all antennas are the bidirectional antenna. The $2 \times 1$ array types of patch can provide directivity in the range $4-4 \mathrm{dBi}$. 


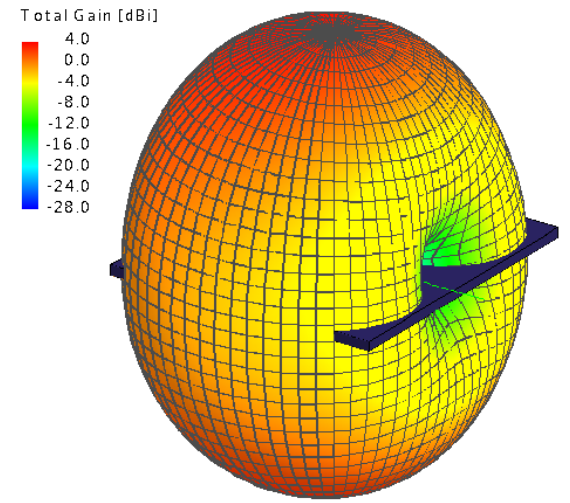

Fig. 6 3D Radiation Pattern

\section{Surface Current Distribution}

The surface current distribution is shown in Fig. 7. It can be seen that there is a significant concentration of the current in the rounded parts of the patch and of the ground plane.

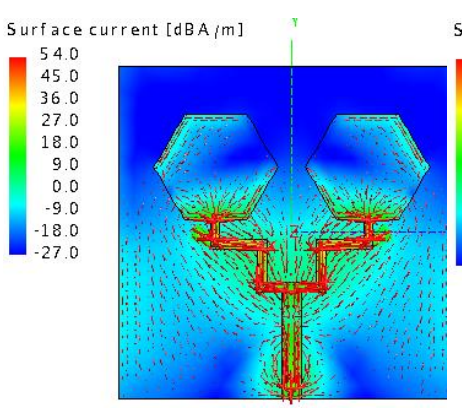

(a)

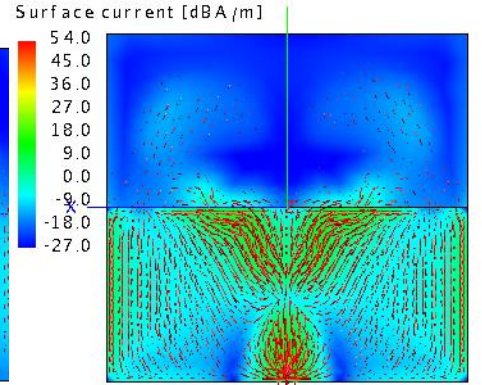

(b)
Fig 7 Current distribution of 2x1 array patched micro strip antenna (a) top view (b) bottom view

\section{CONCLUSIONS}

In this paper, the two hexagonal shape microstrip patch array has been designed for Bluetooth, WiMAX and WLAN applications. A compact $1 \times 2$ array antenna is used to control surface current distribution on the patch antenna to achieve triple-band operation. Good radiation patterns and return loss characteristics, higher gain and low cross-polarization levels was achieved. This triple band antenna is suitable to cover the IEEE 802.11 Bluetooth, WLAN standards of $2.4 \mathrm{GHz}, 5.15-$ $5.35 \mathrm{GHZ}$ and WiMAX band of $3.35 \mathrm{GHz}$.

\section{ACKNOWLEDGMENT}

The author would like to express my gratitude to all colleagues at Mandalay Technological University who have contributed to the preparation of this research work.

\section{REFERENCES}

[1] C.A. Balanis, " Antenna Theory, Analysis and Design," 3rd Edition JOHNWILEY \& SONS, INC, USA, 2005

[2] Dr Homi Bhabha Rd, Pashan, Pune, Antennas and its Applications, Armament Research \& Development Establishment, -411 021

[3] Mohammed Al-Husseini, Member, IEEE, Youssef Tawk, Ali El-Hajj, and Karim Y. Kabalan "A Low Cost Micro strip Antenna for 3G/WLAN/WiMAX and UWB Applications," ACTEA.

[4] Muhammad Mahfuzul Alam, Md Mustafizur Rahman Sonchoy, "Design and Performance analysis of Microstrip Antenna", Progress in Electromagnetic Researrch Symposium Proceedings, Moscow, Russia, August 18-21,2009.

[5] Horng-Dan Chen, Chow-Yen-Desmond Sim, Jun-Yi Wu, and TsungWen Chiu," Broadband High-gain Microstirp Array Antennas for WiMAX Base Station," IEEE Transactions On Antennas And Propagation, Vol.60,No.8, August 2012.

[6] Dipika. S. SagnePrasanna L. Zade, Rahul Batra, "Design \& Implementation of Broadband Triangular Micro strip planar Array For Wireless communication," IEEE Conference on Advanced Communication Control and Computing Technolgies (ICACCCT) 2012.

[7] Ali foudazi, hamid reza hassani, and sajad mohammad ali nezhad,"small UWB planar monopole antenna with added GPS/GSM/WLAN bands,"IEEE Trans. On Antennas and propag., vol. 60,no.6, june, 2012. 